\title{
What makes a compassionate relationship between caregiver and patient? Findings from the 'anniversary' Schwartz Rounds
}

\author{
Joanna Goodrich(10
}

\begin{abstract}
Summary
During the autumn of 2015, 21 Schwartz Rounds were held in England and Wales with the same topic: what makes a compassionate relationship between caregiver and patient? Participants explored themes such as the nature of compassion; what makes compassion difficult, and how to be compassionate, and the discussion within these themes and others are summarised. Many examples of compassionate behaviour provided by participants in the Rounds bear out concepts of compassion found in the academic literature. It is clear that providing consistent compassionate care is challenging. Caregivers discussed what enables compassion and emphasised the importance of the nature of the relationship with their colleagues, as well as with their patients.
\end{abstract}

Keywords: Compassion, Schwartz Rounds, Staff support

\section{Introduction}

\section{What are Schwartz Rounds?}

Schwartz Rounds (Rounds) provide a structured forum where all staff, clinical and non-clinical, come together regularly to discuss the emotional and social aspects of working in healthcare. Started by the Schwartz Center for Compassionate Healthcare, the Point of Care Foundation holds the license in the UK and supports healthcare organisations to introduce and sustain Rounds here. Typically they are hour-long meetings, held monthly with food provided. The hour begins with three or four members of staff (the panellists) presenting a particular topic or patient's case - but with the focus on how caring for that patient (and their family) impacted on them emotionally. The rest of the hour is a facilitated discussion exploring the challenges of caring with compassion. The purpose of Rounds is to understand the challenges and rewards that are intrinsic to providing care, not to solve problems or to focus on the clinical aspects of patient care. Rounds can help staff feel more supported in their jobs, allowing them the time and space to reflect on their roles. Evidence shows that staff who attend Rounds feel less stressed and isolated, with increased insight and appreciation for each other's

Correspondence: joannagoodrich@pointofcarefoundation.org.uk Head of Evidence and Learning, The Point of Care Foundation, 99 Gray's Inn Road, London WC1X 8TY, UK roles. They also help to reduce hierarchies between staff and to focus attention on relational aspects of care $[1,2]$.

The underlying premise for Rounds is that the compassion shown by staff can make all the difference to a patient's experience of care, but that in order to provide compassionate care staff must, in turn, feel supported in their work.

\section{Background}

Ten years ago, during summer 2005, to commemorate its 10th anniversary, the Schwartz Center for Compassionate Healthcare asked hospitals to hold Rounds to discuss the topic, "What Makes for a Compassionate Patient-Caregiver Relationship?" Each facilitator was asked to guide the group discussion and distill practical suggestions for building compassionate patient-caregiver relationships. The discussion format was left to the individual hospital, but suggestions were made for a panel of patients and/or family members, a panel of caregivers (staff), or a focused discussion of the topic. 54 hospitals, over half the hospitals running Rounds in the US at the time, took part [3].

Ten years later with over 130 organisations running Rounds in this country, we (The Point of Care Foundation) wanted to mark the anniversary by repeating the exercise in the UK. This was not a research project but rather a 
chance to record a 'national conversation' about compassion. We thought it would be a good opportunity to explore the nature of compassion and what it means in practice, through conversations amongst people who are thinking about this every month in their Schwartz Rounds.

\section{Definitions of compassion}

First, though, it is useful to look at how compassion has been described and defined by others. The Point of Care programme adopted The Institute of Medicine's definition of patient-centred care, which includes compassion as one of its dimensions $[4,5]$.

Compassion has been defined as 'a deep awareness of the suffering of another coupled with the wish to relieve it' [6]. There is an understanding that compassion goes beyond acts of basic care, and is likely to involve generosity - giving a little more than you have to, and that kindness, and real dialogue are integral [7]. Others have described compassion as a commitment to try to do something to prevent distress, which requires courage and wisdom [8]. There seems to be an understanding that being compassionate is not easy and requires 'acts of work and courage' [9].

Can compassion be taught? In his book 'The Compassionate Mind' Paul Gilbert says that compassion is not as simple as an emotion or a motivation but there are specific skills and abilities which go into compassion (motivation, sensitivity, sympathy, distress tolerance, empathy and non-judgement) which can be taught and learned [10].

Further, compassion is described as including a sensitivity not only to the distress of others but to the distress of self as well [9]. Personal qualities are important, and the notion of self-compassion (as Neff has described [11]) is one of these, and can be cultivated.

Importantly Cole-King and Gilbert emphasise that compassion is not the same as pity, because one person is not weaker or inferior to another in a compassionate relationship [9].

Participants in a workshop run by the Point of Care programme agreed that there were a number of factors that stop compassion [12]. Professional training emphasises the importance of developing an ability to detach oneself from the patient's distress and personal circumstances. Healthcare staff work in an environment where untreatable and terminal illness, disfigurement, suffering, and the pain of loss for patients and families can result in staff distancing themselves as a means of self-protection, which makes it more difficult to feel and show compassion. Isabel Menzies-Lyth famously wrote about the organisational defences that are put up against the anxieties caused by working in such environments. She argues that close contact with suffering, with physical and mental deterioration, with pain and distress and with death, arouses anxiety in all of us, and that actual physical contact with strangers and with their bodies is taboo [13].

In order to protect themselves from such anxiety health professionals need to be sure that they don't identify with patients.

Regular and constant exposure to human suffering causes stress and has a blunting effect, unless there are mechanisms in place to support staff and help them process their experiences.

Burnout produces stress, and at its extreme, produces a lowered sense of personal effectiveness, emotional exhaustion, and depersonalisation of others which can limit compassion, and at its most extreme cause cruelty towards patients [14]. Others have explored whether some patients are easier to look after than others. Some patients are less attractive, more difficult, more frightening and challenging than others: there are always unpopular patients $[15,16]$.

There are a number of factors which enable compassion. Support from colleagues, good team working, and time for reflective practice, are all strategies which can mitigate the diminishing of compassion [17]. Although there is still debate about whether compassion (and empathy) can be formally taught, or measured [18] there is agreement that role modelling by colleagues, is a powerful way of learning how to behave compassionately.

\section{Method}

Members of the Schwartz community in the UK (facilitators and clinical leads of organisations running Schwartz Rounds) were invited by The Point of Care Foundation to take part in a 'national conversation' by choosing the topic 'What makes a compassionate caregiver patient relationship' for their Schwartz Rounds in September 2015. They were invited to send a written account of their Round to us, and guidance was provided (see Appendix) and assurance given that participants would be anonymised.

During the autumn of 2015, 21 Schwartz Rounds were run with this same topic, following the usual format: panelists presented, and facilitated discussion followed. (See Appendix for guidance given to the Rounds facilitators by The Point of Care Foundation) Participants explored themes such as the nature of compassion; what makes compassion difficult, and how to be compassionate. These themes and others are summarised here.

\section{Results}

We received accounts of 21 Rounds from a range of settings, including acute hospitals, mental health services and hospices. Sites approached their Round in a variety 
of ways. Panels were made up of clinicians and nonclinicians and some chose to recount when they or a family member had been a patient. Some chose a patient story to illustrate compassionate care and challenges associated with it. Participants in the Rounds were the usual mix of doctors, nurses, allied health professionals, support, management and administrative staff.

\section{Themes from the Anniversary Rounds}

1. What is compassion? How is it demonstrated? Small acts of kindness

Many spoke about compassion as small acts of kindness. A panellist described how his mother had spoken about a small incident when she was offered a cup of tea when accompanying his father to a hospital appointment and how cared-for she felt by this small act. Another spoke of a nurse taking lunch to a patient in the discharge waiting room knowing that he was going home to an empty house and had been looking forward to a cooked meal. At one Round they talked about the combination of "expert care, everyday kindnesses":

\section{"I don't think you can give compassionate care if you're not giving good clinical care"}

Others wondered whether in order to be compassionate there has to be suffering. One participant quoted the Dalai Lama: "Be kind whenever possible. It is always possible"

Taking time

The theme of having or making time came up often. Demonstrating to a patient that you have time, taking time to listen actively, and be in the moment, is important. The quality of attention is itself an act of compassion.

Using touch

People display compassion in different ways. While it was thought that some show 'honest emotion', you can also show compassion through touch. A physiotherapist talked about this and then reflected that maybe it is easier for physiotherapists to do this because they strip off and examine each other as a large part of their training so they are used to it! Seeing the person in the patient

"When a patient can feel they are a person and not a patient that's a good experience of care"

One of the [hospice] panellists spoke about the belief that what makes a compassionate patient-carer relationship boils down to a shared humanity, and learning to drop perceptions of both ourselves and others, accepting yourself and others and sharing the experience and sharing the relationship. If you see the person first everything else comes into context.

2. How is compassion achieved?

Boundaries: balancing personal and professional This was a predominant theme - when to bring something of yourself personally to the relationship, over and above a purely professional relationship. Is it possible to be compassionate otherwise? This may involve revealing your own emotions in a way that might seem uncomfortable, making yourself a bit vulnerable.

"Going beyond the professional boundaries can allow us to be compassionate"

A Consultant described how a few weeks after one of her patients died her parents came in to thank her, and told her details of the funeral. The Consultant became emotional and cried with the parents - which made her feel compromised. She felt it was not her role as the Consultant to cry. On reflection though she felt she was being human rather than just being professional and had permission to grieve. One of the audience reflected that displaying some emotion is not the same as breaking down.

Another audience member reflected "as a nurse I have struggled with how much to share about myself with patients but the longer I have been a nurse I've learnt that a human to human relationship builds more of a rapport. ...it's when I've let my guard down a little bit that I've had a better connection with patients. There is a fine line that we are always trying to tread"

Giving of ourselves comes at a cost. However, one speaker recounted a situation where she was protected by her colleagues and managers who advised she did not become emotionally involved with a mother whose son was dying on the inpatient unit (because it was close to her own personal situation). But it meant she felt stifled, and the relationship felt unnatural, and she felt her ability to be compassionate was limited. It was however suggested by several that there are limitations to what a person can safely cope with.

In another Round someone observed that it is important to have boundaries within your compassion. You are not in their shoes; you are not going through this experience like they are. Do not over-step the boundaries of compassion. 
Several spoke about how they had 'flexed' the rules to be able to demonstrate compassion. In another Round someone asked

\section{"You're more than just a doctor; you're a person as well. These boundaries are incredibly important and there is a reason for them but sometimes they are too constricting? It makes me think who's benefit are they really there for? Are they there to protect ourselves from feeling? Some don't benefit others so who do they benefit? How can staff be looked after with flexible boundaries without losing control?"}

Can we teach compassion?

One participant thought s/he had learned compassion as part of family life growing up - the seed had been nurtured then. Another observed that s/he felt that society is changing, which is having a detrimental effect on compassion - from a caring society to one where we decide if we like or dislike people. Others thought that compassion is an innate human characteristic - not just feeling the suffering of others but being motivated to do something about it. There were examples given of seeing other staff being compassionate and going out of their way to try to relieve others' suffering. This role modelling has been quite significant for staff and helped them to refocus and to think about their own practice It is tough and takes courage

That it is not easy to be compassionate frequently emerged in discussions:

\section{"Hang on in there even when they push you away"}

"It does upset me very much when I can't make things better and I become overwhelmed with sadness and need a hug myself from my colleagues"

Someone talked about how s/he is always mindful of being told as a junior member of staff that we need to dig deep for courage. An example of this was given in another Round where a member of staff describes visiting a patient following a stroke:

"...he was a young man but he had a stroke and I was frightened to see him as I knew he would look different, and I was unsure what I could say to him, and how he would be able to communicate with me. I had to build up my courage to go, and I will never forget how his whole face lit up when he saw me there. I'm so glad that I didn't abandon him"

3. What helps us to understand compassion? Patients show us compassion Some participants said that particular patients had taught them compassion. It was suggested that very often patients are observing us as much as we are observing them - they are seeking a 'connection'. It was said that patients teach us how to behave; a nurse described how the mother of a teenage patient who had died on the ward came back later in the day to thank the nurse for her care, and how this had meant so much to her, that in the midst of trauma and the death of her daughter the woman had taken the time to come back to say thank you. Being on the other side of care Many spoke about how it was only when they had had experience of being a patient themselves that they truly understood what compassion meant.

I remember being 8 years old in hospital, my Mum had to go home and I was scared and upset and one of the nurses who lived in the nearby nurses' home went home after her shift, collected an assignment she had to do and did it by the bedside to keep me company

A panellist described himself as a confident, resourceful person who did a lot of research about what he wanted for his treatment when he went into hospital, but how this all went out of the window and he became a vulnerable patient, feeling paralysed with anxiety and very afraid and powerless. He remembered the kindness of the attending nurse who came to the bed and held her arm out for him to hold. This small act of kindness was overwhelmingly helpful. Drawing on the experience of being a relative has also revealed the importance of compassion to many. One person told how he was in the hospital chapel while a close relative was having surgery after a very serious accident, and the nurse who had been taking care of him came to find him, and took his hand, and told him that the surgery had been successful. He said that it was the way she did this that alleviated a very difficult situation.

One commented on how the experience of being a patient or a family member receiving care from a professional carer is 'magnified' -being able to recall moments, conversations, words, actions in a way that you wouldn't normally remember things in 'normal' life situations.

It is often the 'non- professional' who makes a difference

A panellist whose father had been dying in hospital described how a healthcare assistant tried to find a $\mathrm{CD}$ player so that her father could have the music he always listened to - and this made a difference. She also took the time to shave him and cut his nails and it was this simple act which restored her father 
back to being her dad and the man she had always known. One person talked about how he felt that the only genuine care for his mother was given by one of the catering staff who took an interest in trying to find foods that his mother might enjoy.

4. Barriers to compassion

Fatigue

This was characterised by compassion being a finite thing, which can be depleted, illustrated by how staff feel when they get home: it is hard to be compassionate at home when it's all used up at work : "if only they would wear pyjamas at home!" Another said: "we see so many patients in a day I have no compassion left for my husband at the end of the day". In another Round someone said "We have a lot of sadness at work - you have to hold it together." She had begun to believe that because of this she had become desensitised and lost the ability to feel and when she had a family crisis of her own was almost reassured by how upset she felt.

Pressure and time

There was a consensus that pressure of work and lack of time are the enemies of compassion. One panellist, working as an F1 doctor felt she had lost compassion at the end of her last placement where there should have been 4 doctors and it was only her and a colleague, the hospital was on black alert and patients 'became a nuisance' and it became a 'nuisance to talk to relatives'

Coping strategies were talked about: one person described hiding in the toilets just to get five minutes breathing space. Another talked about averting her face so that she would not have to engage with the patients.

Type of patient or client

It was agreed at several of the Rounds that it's harder to be compassionate towards some types of patient, particularly if they seem ungrateful: "I was angry - how dare you? - and then felt guilty". It was suggested that some patients may not be able to receive compassion. One person observed that for some people, just being on the receiving end of compassion can make them angry.

Some participants said that they found it more difficult to be compassionate with unlikeable patients -we may have difficult feelings towards our clients and the comment was made that it is then very hard to hold onto your compassion and see things from the client's point of view. In one mental health trust there was some discussion about whether or not it might feel easier to feel compassion for people who can't help themselves, or who are seen to be more disadvantaged at the outset.
Does compassion stop when patients push us away or are in denial about their illness or diagnosis, or prognosis or death? There was a strong belief that being present is sometimes just enough. Not going away or giving up on people is also important. "You can sometimes take a break with people, and sit down together with a cup of tea or coffee."

One panellist, when describing a colleague behaving badly towards him, reflected how it is always worth remembering that we are not always in receipt of all the facts when dealing with others, which might help to explain their behaviour. Others had spoken about forgiving patients' behaviour when they realised what story might lie behind the 'patient' in the bed, or behind the rude and aggressive behaviour of relatives.

5. What can help compassion?

Taking care of ourselves/compassion for oneself

"You need compassion for yourself and for each other before it can be offered to others."

Participants in several of the Rounds talked about the need to take care of themselves and that it is ok not to be perfect".

"There is something about helping yourself and being selfish sometimes in order to build resilience... There are limitations to what a person can safely cope with and a balance between deep unmanageable feelings as humans and being professional. It's complex as these situations involve relationships between humans."

Participants reflected on how we need to be human to be compassionate and that, being human, we will all make mistakes. It is important to acknowledge this.

The support of colleagues

But, as someone observed: "Relationships with colleagues is key - it's not just about selfcompassion". Many discussions touched on how important this was and there was a general consensus that 'everyone gets compassion fatigue' and how important it is to be kind and supportive to colleagues.

It was observed that everyday relationships are particularly difficult in times of change. A word of thanks from a colleague who knows and understands the work involved and truly appreciates it makes a huge difference and is the best sort of reward.

We can create conditions in an organisation There was some discussion about how we can encourage compassion and empathy to thrive in 
organisations, through types of reflective practice, including for example Schwartz Rounds. The irony was noted that often the more pressured we are the less we give ourselves reflective space - when we need it most.

Participants spoke about how Schwartz Rounds helped them to regain compassion:

"You wonder if, when you're busy, you lose compassion, but hearing stories it brings back compassion and it is always there."

There were some reflections on how the Rounds helped participants to normalise their experience and that it helped to discover that other people felt the same as they did: "You're not on your own in how you feel".

\section{Discussion}

The idea for repeating the question 'what makes a compassionate caregiver patient relationship' as a topic for Schwartz Rounds in the UK, ten years after it was done in the U.S. came originally from one of the Rounds facilitators in England, and was taken up by The Point of Care Foundation as an interesting exercise, rather than a formal research project. An invitation to take part was extended via The Point of Care Foundation's website, and was entirely voluntary. Organisations were invited to contact us if interested, and then guidance was sent out. There was no attempt to find a 'representative' group of organisations, but as it happened there was a good mix, and the consistency of themes which arose in the Rounds was striking.

It is interesting also to compare the reflections which emerged in the Rounds in the U.S. ten years ago, with those in the Rounds in the UK last year. Sanghavi found that many of the things said in the Rounds were reflecting on "small acts of kindness" and this was exactly the same ten years on in the UK. It is clear that, like Ken Schwartz, those who talked about being a patient, or a loved one being a patient found that these small acts took on a much greater importance and meaning, and are what is still remembered often years later, when much else is forgotten.

Although participants in the Rounds felt that lack of time prevented them being as compassionate as they would like to be, these small acts do not actually take up time. It is more likely that feeling under pressure is what robs people of the ability to feel that they want to give even as little as a smile or a quick kind word (and patients have become 'a nuisance'). Lack of time and the feeling of being under pressure as a threat to compassion emerged more strongly in our 2015 Rounds (compared with ten years ago in the US) which may not be a surprise in the current NHS context. Ten years ago Rounds participants talked about 'compassion fatigue' and this is still seen as an important theme.

Sanghavi highlights how many caregivers talked about establishing common ground with patients. Our Rounds participants were a little more ambivalent about this, finding that it might be easier to be compassionate where you could either identify with, or share personal information with a patient but that carried risks of crossing a boundary. Some felt uncomfortable mixing personal with professional, and some found they didn't want to do that for their own protection -for fear of being hurt. Others, however, thought it was essential in order to be compassionate and show compassion.

Respect for a patient's individuality emerged as a theme in Sanghavi's paper and our Rounds participants echoed that - there appears to be a consensus that it is a basic principle of compassion to see the person in the patient, and respond to their situation.

In all settings (hospices hospitals and mental health) there was a marked level of agreement about the importance of role models, the importance of compassion for oneself, and the challenges and 'work' of compassion. Most markedly there was an emphasis on how crucial it is for staff to be compassionate to each other as much as to their patients.

As for the nature of compassion itself, the discussion in these Schwartz Rounds bears out much of what the literature on compassion talks about, with many examples of compassion in practice, as well as reflections on what compassion and compassionate relationships mean for people who work in healthcare. Its literal meaning of 'suffering with' was borne out by comments about the importance of just being with a patient when no more can be done. Compassion as requiring 'acts of work and courage' was shown in the Rounds through many examples of acts of kindness, generosity and going the extra mile, and it was clear that often this involved courage. However, it was recognised that this is harder with some patients than others.

Discussion about compassion fatigue, and strategies for protecting oneself from this by distancing, physically and emotionally, resonates with Menzies Lyth's work. The notion of whether compassion is a finite resource, or whether caregivers can be be sustained and supported by their compassion and empathy rather than weakened, as some have suggested [19], appeared to divide Rounds participants.

The idea of self-compassion was discussed, but not in great depth (more as being kind to oneself) and in some cases was dismissed as not as important as compassion towards colleagues and patients.

Cole-King and Gilbert's assertion that a compassionate relationship does not depict one person as to be pitied and therefore inferior to or lesser than the other is 
perhaps the most challenging to enact in practice, but it was illustrated in these Rounds by the insight which emerged from the humble reflection that we as caregivers can learn the meaning of compassion from patients.

\section{Conclusion}

The NHS Constitution says, "The NHS touches our lives at times of most basic human need, when care and compassion are what matter most" [20] Compassionate care (or sometimes the lack of it) has been a focus for the NHS for some time, but there is often very little explanation of what this means in practice. The participants' conversations in these Schwartz Rounds offer an important insight into what a compassionate relationship takes, and how it can be described. It is clear that providing consistent compassionate care is challenging. It is perhaps not surprising that reflective discussions in the UK, and ten years earlier in the U.S. throw up universal themes. However, the discussions in 2015 brought a renewed emphasis on the importance of the notion of a compassionate relationship between patient and caregiver. It was noticeable that caregivers emphasised the importance of a compassionate relationship with their colleagues, but even more striking that they talked about a two-way relationship with patients, and that patients can help their caregivers to learn to be compassionate.

The Schwartz Center for Compassionate Healthcare describes a new paradigm for a compassionate care principle: that it needs a lifetime of support, regular guidance, and repeated reinforcement, and Schwartz Rounds still make an important contribution to this endeavour.

\section{Appendix}

\section{Guidance to sites}

We made the following suggestions to sites:

- Hold a Round in September 2015 which asks the same question: "what makes a compassionate relationship between caregiver and patient?" (you could alter this slightly if you wish eg "...between professional and patient" or '...between staff and patient" or "between you and your patients?" Advertise it with this title or call it 'Anniversary Round' or similar.

- Invite a panel who will speak about this both from the perspective of caring for patients, and/or from the perspective of when they, or someone in their family (or a friend) has been a patient. In this way, as in the Rounds ten years ago, we will get the important patient's perspective, as well as those who provide care.

- We will provide you with an information sheet to give participants, explaining that we will be writing up the themes that emerge from all the Rounds, and that anything they say will be anonymised. You will also be able to explain this at the start of the Round

- Record the Round, either by taking notes or by recording it and providing a transcript. Please send this back to us as soon as possible.

- We will write up the themes that emerge and present our findings at The Point of Care Foundation's annual conference for the Schwartz Rounds community in December 2015.

\section{Acknowledgements}

Thanks to Dr Deborah Allen, Schwartz Rounds facilitator, Derbyshire Healthcare NHS Foundation Trust, for first suggesting the idea for Anniversary Rounds.

Funding

Not applicable (none)

Availability of data and materials

Data will not be shared as individuals could be identified and we assured them this would not happen.

Author's contributions

$J G$ designed the project, analysed the documents, and drafted the manuscript

\section{Competing interests}

The author declares that she has no competing interests.

Consent for publication

As above.

Ethics approval and consent to participate

An information sheet was provided for participants with the following words: "We are asking you to write notes, or record and transcribe the presentation and discussion at your Round and send it to us. We will then pull together the themes that emerge from your Round along with everyone else's and write this up. We plan to present our findings at the annual event for the Schwartz community in December, as well as make a report available on The Point of Care Foundation website, and write a journal paper. Everything that is said in the Rounds will be anonymised, and your organisation will not be identified."

Received: 25 May 2016 Accepted: 18 August 2016

Published online: 06 September 2016

\section{References}

1. Goodrich J. Supporting hospital staff to provide compassionate care: do Schwartz Center Rounds work in English hospitals? J R Soc Med. 2012;105:3.

2. Lown B, Manning C. The Schwartz Center Rounds: evaluation of an interdisciplinary approach to enhancing patient-centered communication, teamwork, and provider support. Acad Med. 2010;85:6.

3. Sanghavi D. What makes for a compassionate patient-caregiver relationship? Jt Comm J Qual Saf. 2006:32:5.

4. Institute of Medicine. Crossing the Quality Chasm: A new health system for the twenty first century. Washington DC: National Academy Press; 2001.

5. Seeing the person in the patient: the point of care review paper. The Kings Fund. 2008. https://www.kingsfund.org.uk/sites/files/kf/Seeing-the-person-inthe-patient-The-Point-of-Care-review-paper-Goodrich-Cornwell-Kings-FundDecember-2008.pdf. Accessed 28 Apr 2016.

6. Chochinov J. Dignity and the essence of medicine: the $A, B, C$ and D of dignity conserving care. Br Med J. 2007;335:184.

7. Frank AW. The renewal of generosity: illness, medicine and how to live. Chicago: The University of Chicago Press; 2004.

8. Cole-King A, Gilbert P. Compassionate care: the theory and the reality. J Holistic Healthcare. 2011;8:3. 
9. Dying is the most grow up thing we ever do so lets take it seriously. Valerie lles. 2014. http://www.reallylearning.com/dying-is-the-most-grown-up-thingwe-ever-do-so-lets-take-it-seriously. Accessed 28 Apr 2016.

10. Gilbert P. The Compassionate Mind : new approaches to life's challenges. London: Constable; 2010.

11. Neff K. Self compassion. London: Yellow Kite; 2011.

12. Enabling compassionate care in acute hospital settings. The King's Fund. 2009. http://www.kingsfund.org.uk/sites/files/kf/field/field_publication_file/ poc-enabling-compassionate-care-hospital-settings-apr09.pdf. Accessed 28 Apr 2016.

13. Menzies-Lyth I. Containing Anxiety in Institutions. London: Free Association Press; 1988.

14. Campling P. Reforming the culture of healthcare: the case for intelligent kindness. The Psychiatric Bulletin. 2013; doi:10.1192.pb.bp.114.047449.

15. Stockwell F. The unpopular patient. In: Rafferty AM, Traynor M, editors Exemplary research for nursing and midwifery. London: Routledge; 2002. p. 23-41.

16. Jeffery R. Normal rubbish: deviant patients in casualty departments. Sociol Health IIIn. 1979;1:1.

17. 17.Enabling compassionate care in acute hospital settings. The King's Fund. 2009. http://www.kingsfund.org.uk/sites/files/kf/field/field_publication_file/ poc-enabling-compassionate-care-hospital-settings-apr09.pdf. Accessed 28 Apr 2016.

18. Muncer S, Lown B, Chadwick R. Can compassionate healthcare be measured? The Schwartz Center Compassionate Care Scale. Patient Educ Couns. 2015;98:8.

19 Graber DR, Johnson JA. Spirituality and healthcare organisations. J Healthc Manag. 2001;46.

20 The NHS Constitution for England. The Department of Health. 2015. https:// www.gov.uk/government/publications/the-nhs-constitution-for-england/ the-nhs-constitution-for-england. Accessed 28 Apr 2016

\section{Submit your next manuscript to BioMed Central} and we will help you at every step:

- We accept pre-submission inquiries

- Our selector tool helps you to find the most relevant journal

- We provide round the clock customer support

- Convenient online submission

- Thorough peer review

- Inclusion in PubMed and all major indexing services

- Maximum visibility for your research

Submit your manuscript at www.biomedcentral.com/submit 